\title{
$A$ adaptação de um curso de inglês do formato EAD para o formato semipresencial: relato de uma experiência com o curso e-Tec Idiomas de língua inglesa
}

\section{The adaptation of teaching materials from a distance learning format to a blended one: an account of an experience with the english course of the e-Tec Languages without borders program}

\author{
Marcelo Cizaurre Guirau ${ }^{1}$ \\ Teresa Helena Buscato Martins Martins²
}

\begin{abstract}
Resumo
O Programa e-Tec Idiomas Sem Fronteiras surgiu de uma demanda apresentada no Fórum de Relações Internacionais (FORINTER) por cursos de idiomas que capacitassem estudantes e servidores da Rede de Educação Profissional, Científica e Tecnológica (EPCT) a participar de projetos de mobilidade internacional e viabilizassem o processo de internacionalização em andamento nos Institutos Federais. Dividido em três módulos de 200 horas cada, o curso de Língua Inglesa do Programa tem como diretrizes: 0 Quadro Europeu Comum de Referência para as Línguas (QECR); os temas transversais; a abordagem comunicativa; o uso de narrativas vinculadas às aulas; 0 conceito de transmídia; a flexibilidade e interatividade dos materiais; e a autonomia do estudante. Apesar de ter sido concebido como um programa de ensino de línguas à distância, percalços financeiros e institucionais impuseram a necessidade de adaptações. Oferecido como curso de Formação Inicial e Continuada (FIC) no campus São Paulo-Pirituba do IFSP, as principais modificações do curso em relação a sua proposta primeira foram a ampliação da carga horária de encontros presenciais e alterações na forma de atuação do formador - gradativamente, ao longo do curso, aproximando-se do papel tradicional do professor. O que apresentaremos aqui é um estudo de caso, de caráter descritivo e exploratório, com a análise de dados quantitativos e qualitativos. A heterogeneidade de formação dos alunos e a pouca familiaridade da maior parte deles com educação à distância estão entre as principais causas das modificações aludidas acima. Neste texto, traremos dados de oferta e uma síntese das experiências e das percepções dos professores de inglês do campus sobre os cursos do Programa e-Tec Idiomas ministrados e sobre a necessidade de adaptar a proposta original às demandas locais.
\end{abstract}

Palavras-chave: Programa e-Tec Idiomas Sem Fronteiras. Ensino de Línguas. Educação à distância.

\section{Abstract}

The e-Tec Languages Without Borders Program was born to answer to a need, identified during the Forum of International Relations (FORINTER), for language courses that could prepare students and staff of the Professional, Scientific and Technological Education Network (EPTC) to engage in international mobility projects and also to assist the Federal Institutes to become international institutions. Divided into three units of 200 hours each, the English course of the Program is oriented by: the Common European Framework of Reference for Languages (CEFR); a selection of cross-cutting themes; the communicative approach; narrative based lessons; the concept of transmedia; the flexibility and interactivity of the materials and the autonomy of the student. Despite the fact of having been designed as an online course, the Program, due to financial and institutional problems, had to undergo adaptations. Offered as a Continuing Education course (FIC) at the Sao PauloPirituba campus of the Federal Institute, the main modifications of the e-Tec English course to reach the necessities of the

\footnotetext{
${ }_{1}$ Pós-doutorando pelo Programa de Pós-graduação em Estudos Linguísticos e Literários em Inglês da Faculdade de Filosofia, Letras e Ciências Humanas da Universidade de São Paulo. Instituto Federal de Educação, Ciência e Tecnologia de São Paulo, São Paulo, Brasil. Orcid: https://orcid.org/0000-0002-3148-7910. E-mail: cizaurre@ifsp.edu.br

2 Doutora em Educação pela Faculdade de Educação, Universidade de São Paulo. Instituto Federal de Educação, Ciência e Tecnologia de São Paulo, São Paulo, Brasil. Orcid: https://orcid.org/0000-0003-0454-0509. E-mail: teresahbmartins@ifsp.edu.br
} 
students of that campus were: an increase of face-to-face interactions and a different role for the instructor - which become, gradually, more akin to the traditional role of the teacher. The research was treated as a descriptive and exploratory case study based on quantitative and qualitative data. The heterogeneous backgrounds of the students and their lack of experience with distance learning were the main reasons for the need of adaptations. In this text we will present data and a synthesis of the teachers experiences and perceptions about working with the e-Tec English course at the campus Sao Paulo-Pirituba and about the adaptations they had to think in order to better fulfill their students' needs.

Keywords: e-Tec Languages Without Borders Program. Language Teaching. Distance Learning.

\section{Programa e-Tec Idiomas Sem Fronteiras}

A educação profissional no Brasil percorreu um grande caminho a partir de 1909. Sua primeira denominação foi Escolas de Artífices, passando para Liceu Industrial, Escola Industrial, Escola Técnica, Escola Técnica Federal e Cefet. Decorridos cem anos, temos hoje os Institutos Federais de Educação, Ciência e Tecnologia, que são a materialização das políticas públicas em educação profissional no Brasil.

Uma das preocupações dos Institutos Federais é com a democratização do acesso a cursos públicos e gratuitos, sendo que uma das formas de viabilizar a oferta de educação profissional foi a criação de cursos à distância, em regime de colaboração entre União, Estados, Distrito Federal e municípios. Para isso, foi criado o sistema Rede e-Tec Brasil, com o Ministério da Educação sendo o responsável pela assistência financeira na elaboração dos cursos.

Em 2011, com a aprovação do Decreto $n^{0} 7.642$, de 13 de dezembro, iniciou-se um processo de internacionalização do ensino nas instituições federais com, entre outras medidas, a criação do Programa Ciência sem Fronteiras. Ele tinha como objetivo: a expansão da ciência, da tecnologia e da competitividade brasileira por meio do intercâmbio e da mobilidade internacional em universidades, instituições de educação profissional e tecnológica e centros de pesquisa estrangeiros de excelência; abertura e preparação dos campi da Rede Federal de educação em nível superior para atrair ao Brasil jovens talentos e pesquisadores estrangeiros de elevada qualificação, em áreas de conhecimento definidas como prioritárias (BRASIL, 2011).

Com a intensificação dos processos de internacionalização, o conhecimento de línguas estrangeiras tornou-se uma necessidade, não só para os estudantes brasileiros que iam frequentar universidades em todo o mundo a partir do Programa Ciências sem Fronteiras, mas também para os servidores das instituições federais, que receberiam estudantes de outros países. Por isso, o Conselho Nacional das Instituições da Rede Federal de Educação Profissional e Tecnológica (CONIF) instituiu uma política de ensino de línguas estrangeiras por meio do Fórum dos Assessores Internacionais (FORINTER), o qual propôs à Secretaria de Educação Profissional e Tecnológica (Se-Tec) o desenvolvimento de três cursos de línguas a serem implantados pela Rede e-Tec: Língua Inglesa, Língua 
Espanhola e Língua Portuguesa para Estrangeiros. Esses cursos seriam desenvolvidos como cursos de Formação Inicial e Continuada (FIC), sendo que a produção de materiais didáticos ficou a cargo do Instituto Federal Sul Rio Grandense (IFSUL), tomando como base o conhecimento do Núcleo de Produção e Tecnologia Educacional (NPTE), criado em 2012 por essa instituição. Essa conexão do curso aos propósitos de internacionalização do ensino e da pesquisa na Rede Federal está manifesto no documento de orientação docente do Programa, que elege como seu principal objetivo "preparar os estudantes para enfrentar provas de proficiência linguística e intercâmbios nos diversos países disponíveis pelo Programa Ciências Sem Fronteiras" (DA SILVA et al, 2015, p. 9).

Em suas diretrizes, o Programa e-Tec Idiomas define sua filiação às orientações da Abordagem Comunicativa para o ensino/aprendizagem de Língua Estrangeira, que está voltada para a comunicação cotidiana. Assim, valoriza-se o papel da língua oral e contempla-se a língua não apenas a partir de sua estrutura/forma, gramática e léxico, mas também em termos das funções comunicativas que ela executa em atividades socialmente reconheciveis.

Richards e Rodgers (1986, p. 64-86) observam dois objetivos para a abordagem comunicativa: fazer da competência comunicativa o objetivo do ensino de Língua Estrangeira; desenvolver procedimentos para ensinar as quatro habilidades (leitura, escrita, fala e escuta), de modo a não separar o conhecimento linguístico da comunicação.

Na Abordagem Comunicativa, entende-se que a língua é aprendida a partir do seu uso, na comunicação, sem uma dependência estrita da interferência e do controle do professor. No material produzido para o Programa e-Tec Idiomas sem Fronteiras, observa-se que o aprendiz é exposto a situações tão próximas quanto possível da aquisição natural, não dirigida, uma vez que a troca de significados é central ao processo de comunicação. Para uma reflexão sobre o que é ser comunicativo na Abordagem Comunicativa, Almeida Filho (1993, p.42) argumenta:

Ser comunicativo significa preocupar-se mais com o próprio aluno enquanto sujeito e agente no processo de formação através da língua estrangeira. Isso significa menor ênfase no ensinar e mais força para aquilo que abre ao aluno a possibilidade de se reconhecer nas práticas do que faz sentido para a sua vida do que faz diferença para o seu futuro como pessoa (ALMEIDA FILHO, 1993, p. 42).

Um dos mais educacionalmente promissores recursos do material do Programa e-Tec Idiomas para o trabalho com a Abordagem Comunicativa é a vinculação das aulas a uma narrativa contínua. Além de seu objetivo primeiro de vincular o interesse do aluno pela narrativa ao progresso das lições, esse recurso didático se presta como base para o desenvolvimento de habilidades linguísticas, a partir da perspectiva que orienta o curso, como consta nas orientações para o formador: 


\begin{abstract}
Além de atuar como um dispositivo de engajamento, a história ilustra a aplicação prática de situações comunicativas e conteúdos trabalhados em cada aula, contribuindo para 0 desenvolvimento e/ou aprimoramento de habilidades como leitura e compreensão auditiva. As situações apresentadas na história permitem, ainda, a abordagem de aspectos da comunicação não verbal e de comportamentos paralinguísticos, que possibilitam a ampliação de significados e potencializam o processo de aprendizagem dos estudantes. (DA SILVA et al, 2015, p. 15).
\end{abstract}

O advento da Tecnologia de Informação e da Comunicação (TICs) e sua aplicação no processo de ensino na Abordagem Comunicativa motivou novas reflexões, interações e modificou a dinamicidade na aprendizagem da língua inglesa, uma vez que o ensino passa a ser mediado pelo computador e a interação, visando à aprendizagem, se dá à distância ou em comunidades virtuais. É uma nova forma de pensar a sala de aula, não mais como um espaço pré-definido, rígido, mas com a possibilidade de extrapolação, o que modifica o papel do professor. Ele passa a ser facilitador da aprendizagem, motivando seu aluno a um nível adequado à geração de ideias e a visão do aprendiz como responsável pelos resultados de sua aprendizagem.

Para promover um resultado que contemplasse uma aprendizagem do nível básico ao intermediário do idioma, o curso é constituído de três módulos (A1, A2, B1), conforme o Quadro Europeu Comum de Referência para Línguas. Também, as unidades são ancoradas na plataforma Moodle, por meio da qual os estudantes podem interagir, de forma síncrona ou assíncrona, com os tutores, a fim de sanar dúvidas ou mesmo para buscar apoio na realização das atividades.

Além disso, os estudantes contam com material impresso, composto por três livros para cada módulo e um DVD com o conteúdo dos livros. As aulas são apresentadas por meio de narrativas, com vídeos de animação, de forma interativa, abordando diferentes culturas, sempre seguidas de atividades das mais diversas tipologias ("múltipla escolha, verdadeiro ou falso, sequência, relacione, completar lacunas, ponto ativo, arrastar e soltar, atividades com as ferramentas do AVA Moodle") (DA SILVA et al, 2015, p. 29).

\title{
2 Metodologia de pesquisa
}

Para embasar a discussão sobre o processo de adaptação de materiais aqui relatado, dentre as possibilidades de estratégias metodológicas a serem utilizadas, escolhemos, primeiramente, realizar uma pesquisa documental. Ela resultou em levantamentos sobre o histórico dos institutos federais $\mathrm{e}$ sobre a elaboração do material do e-Tec Idiomas Sem Fronteiras, ambos relacionados ao foco principal deste estudo. Em seguida, os procedimentos de pesquisa foram dirigidos para o levantamento de dados 
sobre os estudantes inscritos entre os anos de 2016 e 2019 nos cursos FIC "e-Tec Idiomas Sem Fronteiras" do Instituto Federal de São Paulo, campus São Paulo-Pirituba. Dessas ações de pesquisa resultou o presente estudo de caso, o qual tem propósito descritivo e exploratório, desenvolvido a partir da análise qualitativa e quantitativa dos dados.

\section{Dados e experiência do campus São Paulo-Pirituba com o curso de Língua Inglesa do Programa e-Tec Idiomas Sem Fronteira}

O campus Pirituba (PTB) faz parte do Plano de Expansão da Rede Federal de Educação Profissional e Tecnológica. Está localizado na Região Noroeste do município de São Paulo, Estado de São Paulo, o maior do país, com área de $1525 \mathrm{~km}^{2}$ e mais de 11,5 milhões de habitantes, desconsiderando-se a grande São Paulo. É a cidade mais rica do Brasil e a quarta maior no mundo, onde setores de indústria, serviços e comércio propiciam um vasto campo de atuação e empregabilidade.

Para a definição dos eixos tecnológicos do campus, foram distribuídos, ao todo, 2163 questionários nas três primeiras audiências. Eles circularam pela região em escolas, empresas, comércios e instituições que atendem à comunidade. Também foram realizadas quatro audiências públicas, sendo que as três primeiras (realizadas em 14 e 28 de novembro de 2015, nos bairros de Pirituba e Perus, respectivamente, e em 12 de dezembro de 2015, no bairro da Brasilândia) foram para consulta pública, a fim de definir os eixos tecnológicos do campus. A quarta foi realizada a 25 de junho de 2016, na própria instituição.

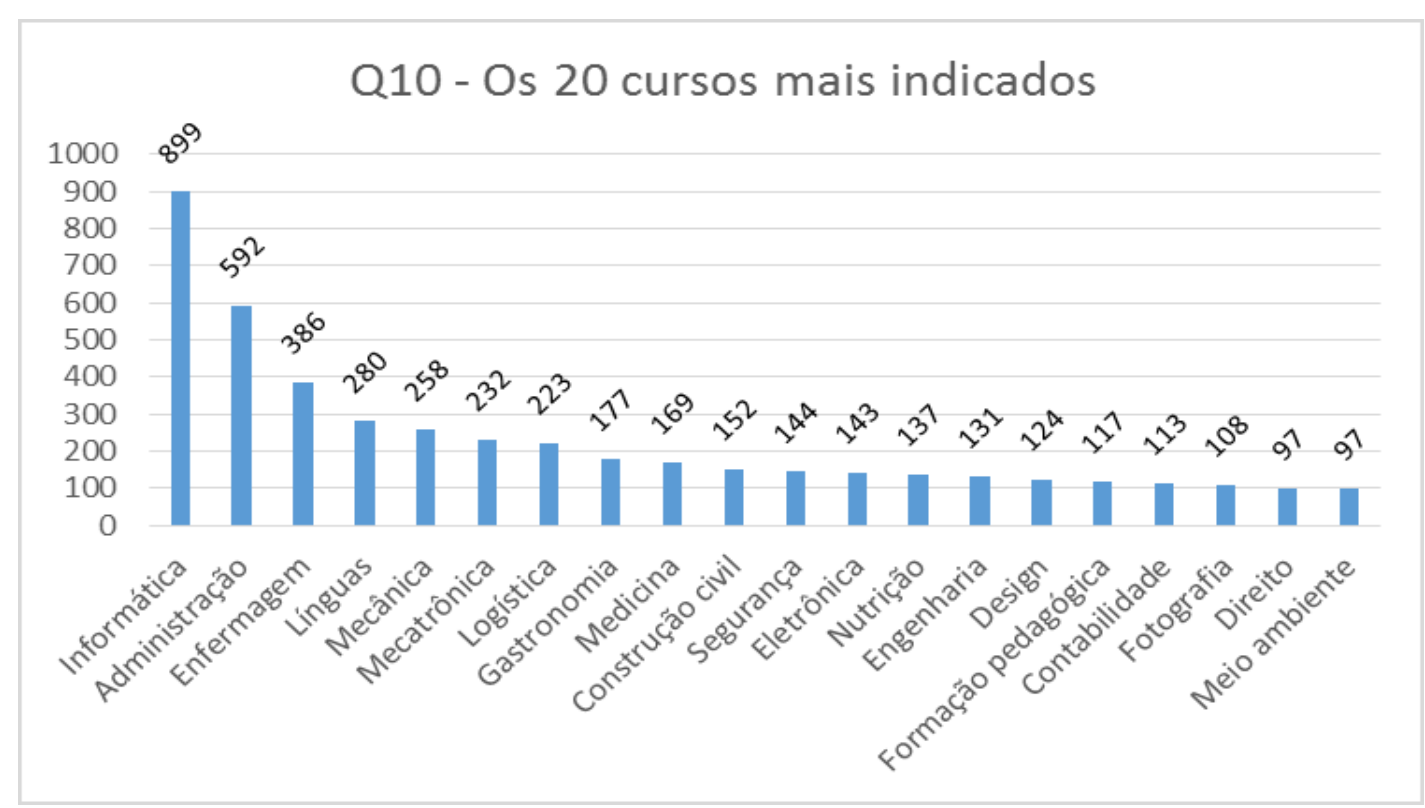

Gráfico 1. Eixos mais indicados nas audiências públicas no Pirituba.

Fonte: Elaborado pelos autores.

LínguaTec, Instituto Federal de Educação, Ciência e Tecnologia do Rio Grande do Sul, Bento Gonçalves v. 5 , n. 2 , p. 296-309, nov. 2020. 
Os questionários identificaram cerca de 297 cursos diferentes. Entre eles, o Gráfico 1 aponta os vinte mais indicados. Do total, 899 questionários optaram pelo curso de Informática, 592 pelo de Administração, 386 por Enfermagem, e 280 por Línguas. A indicação por Línguas, associada ao curso de Licenciatura em Letras, aparece em $4^{\circ}$ lugar entre os 20 cursos mais indicados do total de 297. Esses dados ajudam a evidenciar e compreender o grande anseio dos participantes (membros de conselhos e comunidades próximas e moradores da região, basicamente) por cursos de idiomas.

Nesse primeiro momento, foram oferecidos cursos de Língua Inglesa, pois a região é um grande polo de atividades logísticas, com vários centros de distribuição de produtos e várias empresas relacionadas à área de computadores, o que faz a língua inglesa ser um dos requisitos básicos na contratação de empregados. Não foi oferecido o curso de Espanhol, pois não tínhamos ainda um docente da disciplina. Além disso, esse interesse determinou a criação, no campus, da licenciatura em Letras, com habilitação em Língua Portuguesa e Língua Inglesa. Com base nisso, o curso online original foi pensado em três módulos, cada um com uma carga horária prevista de 200 horas, conforme mostra a Figura 1.

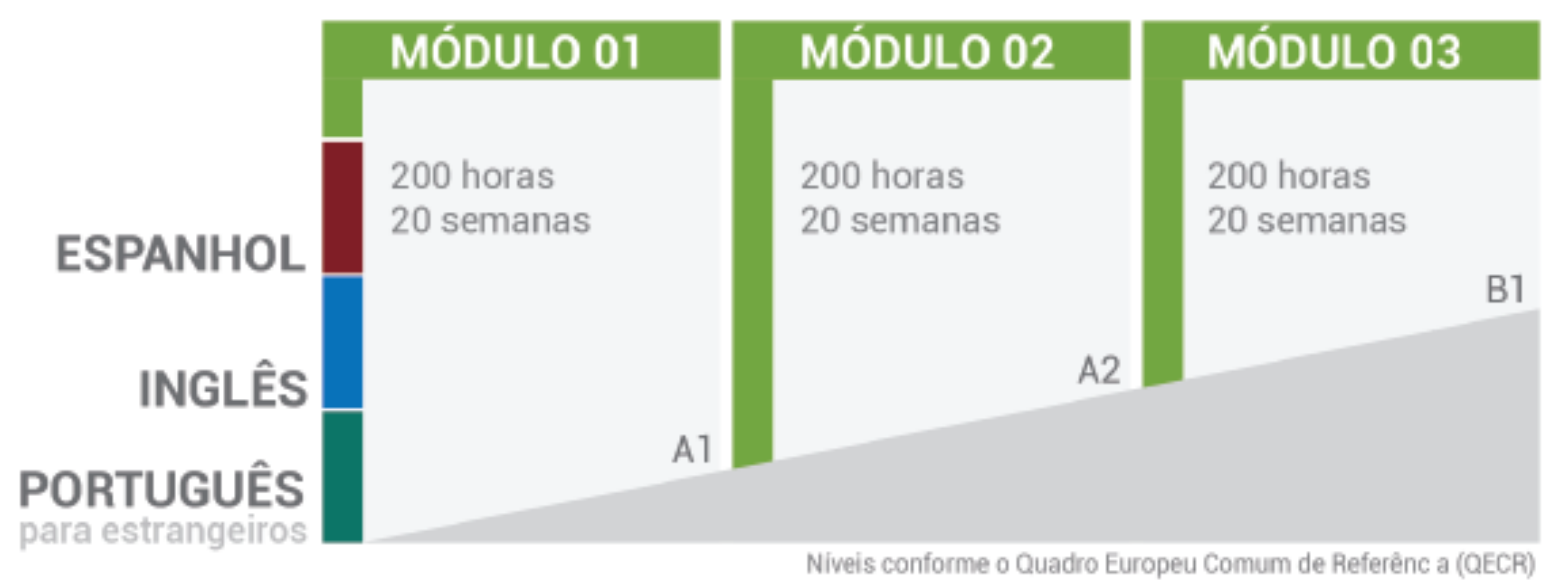

Figura 1. Módulos do curso.

Fonte: DA SILVA et al, 2015.

A disponibilidade de acesso ao material do Programa e-Tec Idiomas Sem Fronteiras em plataforma online tornou mais fácil a sua utilização nos cursos FIC de Língua Inglesa, uma vez que isso possibilitava ao mediador um acompanhamento mais preciso do desempenho dos alunos no curso e também o acesso a um meio eficiente de comunicação com os estudantes e envio de devolutivas. 


\section{LÍNGUATEC}

\section{MÓDULO 01}

\begin{tabular}{|c|c|c|c|c|}
\hline $1{ }^{\text {a SEMANA }}$ & $2^{2}$ a $7^{a}$ SEMANA & $8^{\mathrm{a}}$ e $13^{\mathrm{a}}$ SEMANA & $14^{a}$ e $19^{a}$ SEMANA & $20^{\circ}$ SEMANA \\
\hline AMBIENTAÇĀO & CADERNO 01 & CADERNO 02 & CADERNO 03 & AVALIAÇĀO FINAL \\
\hline \multirow[t]{6}{*}{ Encontro presencial } & Aula 01 & Aula 07 & Aula 13 & \multirow[t]{6}{*}{ Encontro presencial } \\
\hline & Aula 02 & Aula 08 & Aula 14 & \\
\hline & Aula 03 & Aula 09 & Aula 15 & \\
\hline & Aula 04 & Aula 10 & Aula 16 & \\
\hline & Aula 05 & Aula 11 & Aula 17 & \\
\hline & Aula 06 & Aula 12 & Aula 18 & \\
\hline
\end{tabular}

Figura 2. Divisão das Aulas.

Fonte: DA SILVA et al, 2015.

A oferta de cursos de Inglês no campus Pirituba foi uma forma de atender a uma grande demanda ${ }^{3}$ das comunidades externa e interna. Entre seus benefícios, está o fato de auxiliar o processo de internacionalização do Instituto Federal de São Paulo, com a capacitação dos servidores, para atender estudantes estrangeiros que venham a frequentar o campus. Os números dos cursos e-Tec realizados estão presentes nos Gráficos 2, 3, 4, 5 e 6. Após eles, há a Tabela 1, a partir da qual será feito um estudo mais aprofundado.

Em agosto de 2016, o curso de Formação Inicial e Continuada (FIC) "e-Tec Idiomas sem Fronteiras-Língua Inglesa" foi ofertado no instituto na forma presencial. Entretanto, foi seguida a mesma estrutura do curso online. Por questões de distribuição da carga horária docente no campus, o número de horas dos encontros presenciais variava de 50 a 60 horas por módulo, dependendo da turma, por 15 semanas, em média. Foram oferecidas 40 vagas e tivemos 388 inscrições, como se percebe no Gráfico 2. Basicamente, foram oferecidas turmas e-Tec 1, e poucas turmas 2. 0 curso nesse formato FIC, inicialmente, foi pensado de forma a adotar a mesma divisão em três módulo do curso online. Assim, teríamos os cursos FIC e-Tec 1, 2 e 3.

3 O número de inscritos nos cursos FIC "e-Tec Idiomas sem Fronteiras-Língua Inglesa" confirma essa demanda. Sendo os cursos mais procurados do campus, esses FICs de Língua Inglesa registraram uma média de 179 inscritos nos cinco semestre em que foram oferecidos: 2016-2 (388); 2017-1 (121); 2017-2 (168) e 2018-1 (167), 2019-2 (54). 


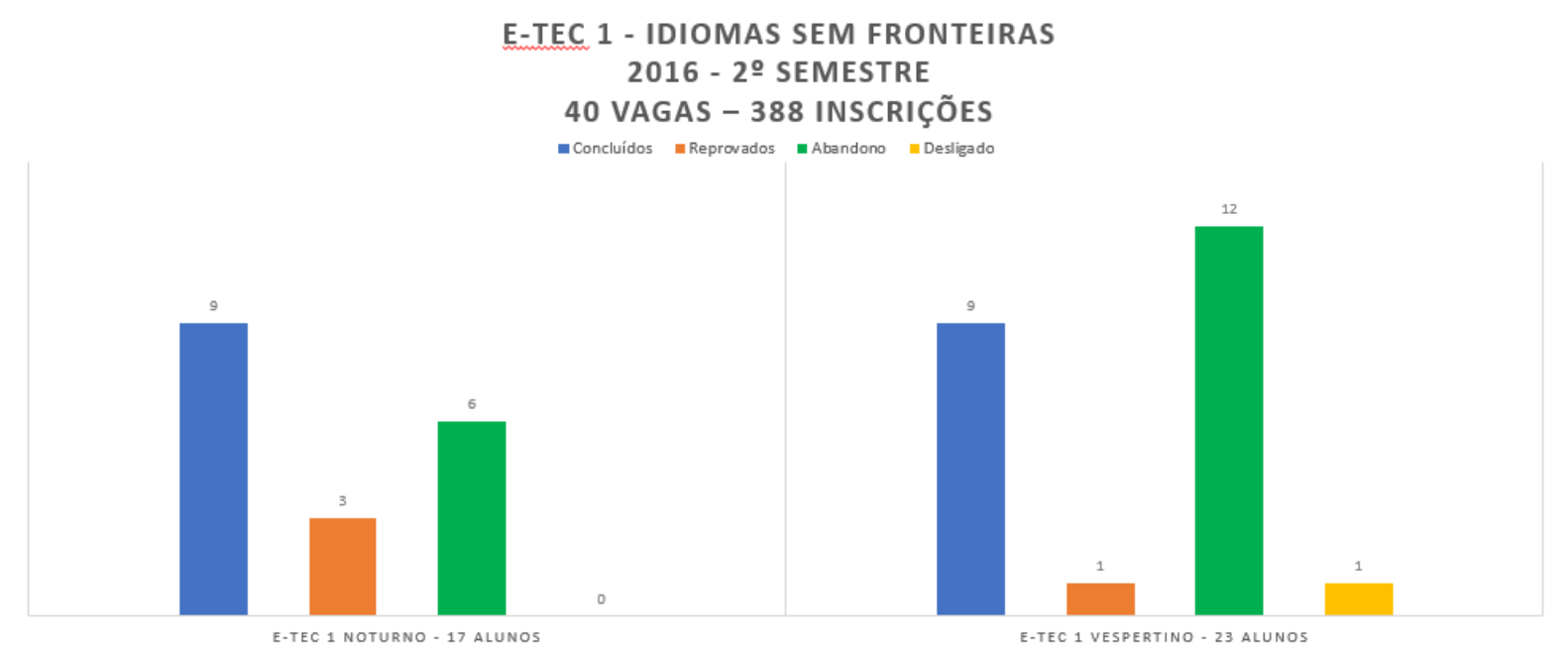

Gráfico 2. Dados dos alunos matriculados no curso FIC "e-Tec Idiomas sem Fronteiras" (IFSP-PTB) - Segundo Semestre de 2016.

Fonte: Elaborado pelos autores.

A partir de 2017, com a implantação dos cursos regulares do campus (sobretudo a Licenciatura em Letras), a disponibilidade de carga horária docente para oferta de cursos FIC diminuiu bastante. Ainda assim, foram ofertadas 90 vagas no primeiro semestre, para as quais se candidataram 121 candidatos, assim como mostra o Gráfico 3. A queda de vagas ocorreu no segundo semestre, quando, conforme 0 Gráfico 4, foram ofertadas 50 vagas, que tiveram 168 inscritos.
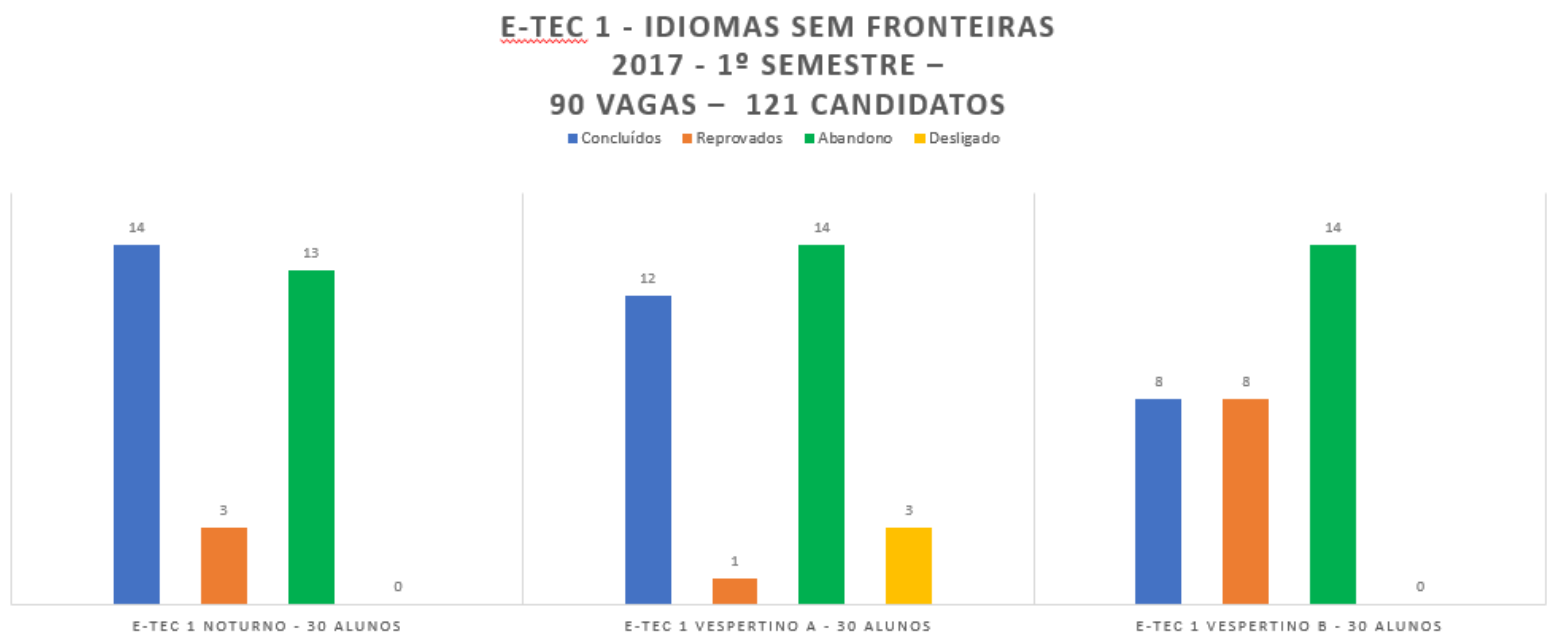

Gráfico 3. Dados dos alunos matriculados no curso FIC "e-Tec Idiomas sem Fronteiras" (IFSP-PTB) - Primeiro Semestre de 2017.

Fonte: Elaborado pelos autores. 


\section{E-TEC 1 - IDIOMAS SEM FRONTEIRAS \\ 2017 - 2 SEMESTRE \\ 50 VAGAS - 168 INSCRITOS \\ - Concluídos $\mid$ Reprovados $=$ Abandono $=$ Desligados}
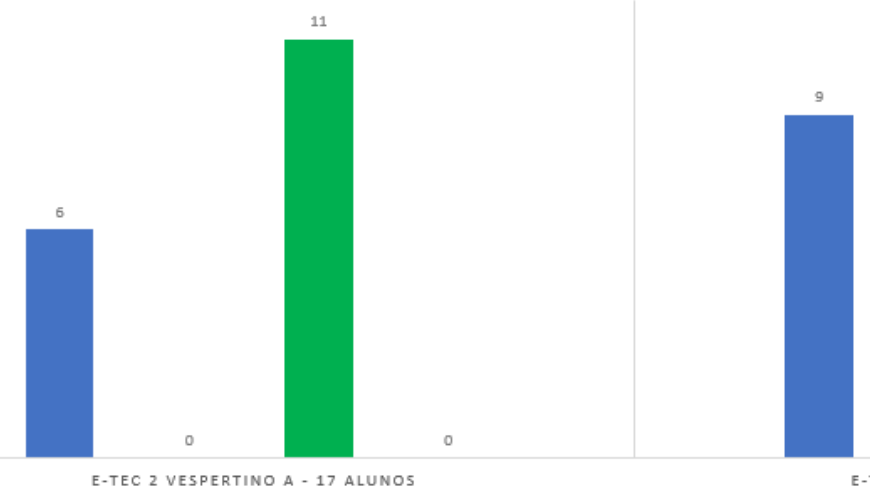

Gráfico 4. Dados dos alunos matriculados no curso FIC "e-Tec Idiomas sem Fronteiras" (IFSP-PTB) - Segundo Semestre de 2017.

Fonte: Elaborado pelos autores.

O ano de 2018, representado no Gráfico 5, teve a oferta de apenas 40 vagas no primeiro semestre, uma vez que o campus ainda não havia contratado todos os professores e a sua carga horária ultrapassaria o limite de aulas permitido caso os mesmos assumissem cursos FIC. Por isso, ficou impossibilitada a continuação da oferta dos cursos FIC "e-Tec Idiomas sem Fronteiras-Língua Inglesa" pelos docentes no segundo semestre.

\section{E-TEC 1 - IDIOMAS SEM FRONTEIRAS}

2018 - 1 SEMESTRE

40 VAGAS - 167 INSCRITOS

a Concluídos a Reprovados a Abandono
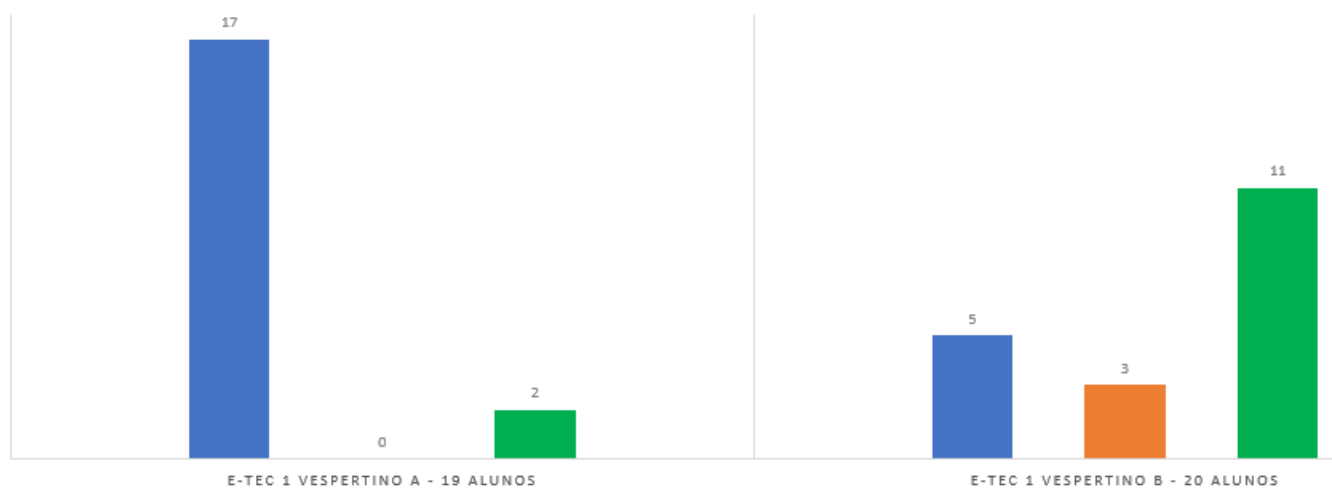

E-TEC 1 VESPERTINO B - 20 ALUNOS

Gráfico 5. Dados dos alunos matriculados no curso FIC "e-Tec Idiomas sem Fronteiras" (IFSP-PTB) - Primeiro Semestre de 2018.

Fonte: Elaborado pelos autores

No segundo semestre de 2019 , foram ofertadas 60 vagas na forma de projeto de ensino. Dois alunos monitores, supervisionados por um professor, assumiram as aulas.

LínguaTec, Instituto Federal de Educação, Ciência e Tecnologia do Rio Grande do Sul, Bento Gonçalves v. 5 , n. 2, p. 296-309, nov. 2020. 


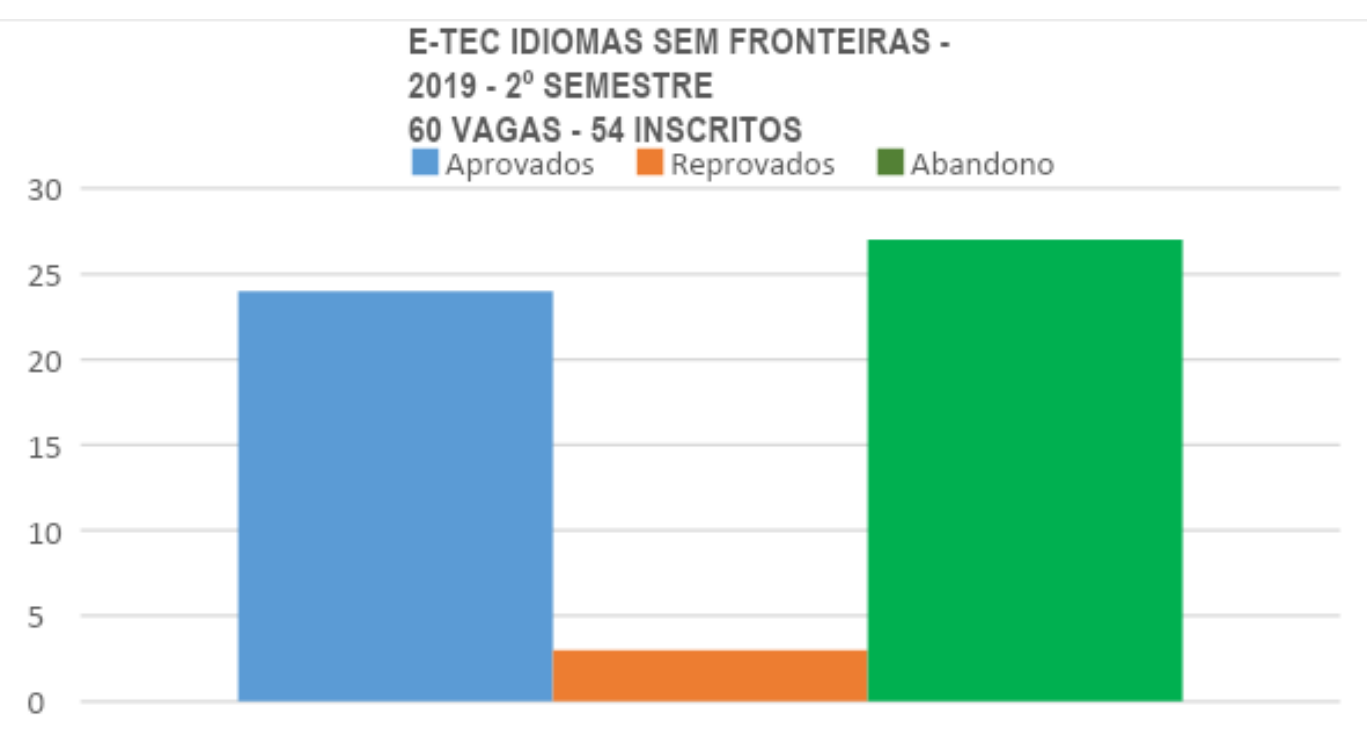

Gráfico 6. Dados dos alunos matriculados no curso FIC "e-Tec Idiomas sem Fronteiras" (IFSP-PTB) - Segundo Semestre de 2019.

Fonte: Elaborado pelos autores.

Para melhor visualização, estão compilados na Tabela 1 os dados dos cursos FIC "e-Tec Idiomas sem Fronteiras-Língua Inglesa" oferecidos no campus São Paulo-Pirituba de 2016 a 2019.

\begin{tabular}{|c|c|c|c|c|c|c|}
\hline $\begin{array}{l}\text { Ano/semest } \\
\text { re }\end{array}$ & $\begin{array}{l}\mathrm{N}^{0} \text { de } \\
\text { vagas }\end{array}$ & $\begin{array}{c}\mathrm{N}^{0} \text { de } \\
\text { inscritos }\end{array}$ & Concluídos & Reprovados & Abandonos & Desligamentos \\
\hline $2016-2$ & 40 & 388 & 18 & 4 & 18 & 1 \\
\hline $2017-1$ & 90 & 121 & 34 & 12 & 41 & 3 \\
\hline $2017-2$ & 50 & 168 & 15 & 0 & 19 & 1 \\
\hline $2018-1$ & 40 & 167 & 22 & 3 & 13 & 0 \\
\hline $2019-2$ & 60 & 54 & 24 & 3 & 27 & 0 \\
\hline TOTAL & 280 & 898 & 113 & 22 & 140 & 5 \\
\hline
\end{tabular}

Tabela 1. Quadro resumido dos resultados dos cursos FIC e-Tec Idiomas sem Fronteiras-Língua Inglesa - IFSP-PTB. Fonte: Elaborado pelos autores. 
Podemos observar que o número total de alunos que concluíram os cursos (113) é bem baixo se comparado ao total de inscritos (898). Além desse baixo índice de concluintes, há um elevado número de alunos que abandonaram o curso. De fato, há sempre alguma evasão nos cursos de formação continuada. Ela se dá, em parte, pelo processo de distribuição das vagas, que, em muitos casos - assim como nos cursos de idioma e-Tec - é feito por sorteio. Dessa forma, as turmas costumam ser muito heterogêneas, abrigando de estudantes secundaristas à pós-graduados. Como cursos de diversas áreas são ofertados pelos professores na forma de extensão, muitos alunos iniciam mais de um e tentam conciliá-los por um tempo. Depois, optam pelo abandono, ou, poucos, pelo desligamento de um dos cursos.

No caso dos cursos FIC "e-Tec Idiomas sem Fronteiras", a exigência para a inscrição no sorteio era o Ensino Fundamental completo. Em algumas turmas, foi exigido que o aluno participasse de um teste de classificação (placement test) cujo objetivo era avaliar diferentes níveis de desempenho desses alunos e posicioná-los em classes cujos alunos tivessem níveis linguísticos semelhantes. Entretanto, a ideia do teste afastou alguns alunos, sobretudo aqueles que haviam interrompido os estudos há bastante tempo. $\mathrm{O}$ que se verificou, em conversas com alguns desses alunos, é que muitos deles desejavam retomar o estudo do idioma estrangeiro no nível básico, uma vez que julgavam o seu conhecimento da língua muito elementar.

Podemos observar, por relatos de alunos, que muitos trazem à tona a ideia de um imaginário recheado de crenças sobre a aquisição de uma nova língua. Almeida Filho (1993, p. 13) definiu essas crenças com o termo "cultura de aprender", ou seja, "maneiras de estudar e de se preparar para o uso da língua-alvo consideradas como 'normais' pelo aluno, e típicas de sua região, etnia, classe social e grupo familiar, restrito em alguns casos, transmitidas como tradição, através do tempo, de uma forma naturalizada, subconsciente, e implícita".

Além disso, houve poucas turmas de e-Tec 2 e nenhuma de 3, o que impossibilitou uma melhor alocação dos alunos em níveis. Assim, os testes de nivelamento só foram realizados pelos professores que atuaram nos níveis 1 e 2 no mesmo semestre. Com a possibilidade de escolher entre diversos cursos, a exigência de um teste de nivelamento se revelou um elemento fortemente dissuasivo para 0 potencial aluno "e-Tec Idiomas sem Fronteiras". Isso foi observado pelos professores ministrantes dos cursos no momento da inscrição. Muitos alunos hesitaram e questionaram a necessidade do teste. $A$ maioria manifestou interesse em iniciar o curso do nível básico, independentemente do resultado do teste de nivelamento. 
Assim, à heterogeneidade das turmas (em nível de escolaridade, faixa etária, faixa de renda, tempo disponível para os estudos etc...), já natural nos cursos FIC, acrescentou-se a discrepância de níveis de compreensão no idioma alvo, o que resultou em turmas multiníveis com alta variação.

O planejamento inicial dos cursos previa que os professores mediassem a relação dos alunos com o material online, estimulando o desenvolvimento de uma postura autônoma. No entanto, o que se apresentou aos docentes foi um grande déficit de letramento digital dos alunos e uma tendência de buscarem a resolução de suas dificuldades na intervenção do professor, e não no trabalho com o material online.

No começo das aulas, era comum que os alunos solicitassem do professor direcionamentos e explicações que já constavam no material. Mesmo com as explicações dadas nas primeiras aulas sobre a dinâmica do curso online, a dependência do aluno em relação ao professor resistia. Com as classes heterogêneas, o trabalho em duplas se mostrou um recurso eficiente para diminuir a alta demanda de atenção que ocupava o professor quase exclusivamente com a resolução de dificuldades de uso do material. Porém, o trabalho em dupla, como observamos na prática das aulas, funciona provisoriamente, uma vez que ele compromete o ritmo de andamento do curso para o aluno que ajuda e não necessariamente resulta em conquista de autonomia para o aluno que é ajudado.

De fato, o que observamos e o que percebemos na fala de muitos alunos é uma necessidade de interação humana no processo educacional, sobretudo em cursos de idiomas. Mesmo diante das orientações e facilidades do material online, os alunos queriam solicitar a intervenção do professor. Essa demanda se revelava claramente nas correções das atividades. Mesmo para as com correção e feedback automáticos, os alunos insistiam em refazer as atividades com a condução do professor, apesar da facilidade do andamento dessas atividades na plataforma online. Aqui, nos parece emergir uma dificuldade corrente na utilização das TICs para ensino de idiomas: como criar meios de suprir, em cursos de idioma em EaD, a falta da presença humana.

No planejamento dos cursos FIC "e-Tec Idiomas sem Fronteiras", previmos que os encontros presenciais poderiam proporcionar uma oportunidade de um foco maior no desenvolvimento de habilidades orais, algo que é bem mais limitado no curso online. Nele, as atividades orais previstas envolviam gravação de áudio e feedback do professor. Novamente, as dificuldades de muitos dos alunos com computadores limitavam esse trabalho. Por outro lado, o próprio instrumento não era muito eficiente e as gravações eram enviadas com cortes e baixa qualidade de som. Muitas dessas atividades puderam ser realizadas em sala de aula, em vez de feita na plataforma do curso. Esse foi um grande ganho do curso presencial, o que levanta questões sobre como desenvolver a competência oral em cursos de 
idioma em EaD. Observamos, no entanto, que o trabalho com essa competência demanda um tempo muito maior do que o disponível para esses FICs, o que faz com que seja necessário um esforço do aluno para além do tempo em sala de aula.

\section{Conclusões}

Baseado nas experiências dos professores que atuaram nos cursos FIC "e-Tec Idiomas sem Fronteiras" no campus São Paulo-Pirituba, nos dados recolhidos e em leituras teóricas aqui referidas, concluímos que os problemas com letramento digital são causa importante do insucesso de muitos alunos nos cursos. Tal letramento é adquirido, desenvolvido e aperfeiçoado ao longo dos cursos oferecidos na modalidade EaD. $O$ curto tempo de que dispúnhamos não viabilizava o trabalho simultâneo entre a enorme quantidade de conteúdos do próprio curso e entre as demandas de letramento digital de um curso semi-presencial. Além disso, percebemos que faltava motivação, interesse e autonomia dos alunos para que pudessem fazer uso das possibilidades de desenvolvimento do ensino/aprendizagem de Língua Estrangeira por meio da EaD. Apesar da crescente utilização de TICs e da necessidade de autonomia nos processos educacionais na EaD, evidencia-se a necessidade da interação humana e da qualidade dessa interação para a aprendizagem de LE (CRISTÓVÃO, 2001).

Quanto ao aprendizado das habilidades necessárias para uma boa comunicação em inglês, observamos o seguinte: apesar dos alunos disporem, nos FICs aqui analisados, das aulas presenciais para desenvolver a competência oral - ao contrário da proposta original do Programa e-Tec Idiomas Sem Fronteiras -, percebeu-se que apenas esses momentos não foram suficientes para garantir 0 desenvolvimento da habilidade de produção oral em língua inglesa.

Por fim, entendemos que o processo seletivo adotado para os cursos FIC no campus (sorteio) determinou a formação de turmas muito heterogêneas, o que contribuiu para o elevado índice de abandono. A prática das aulas reforçou a necessidade de divisão dos alunos em turmas por nível. A utilização de um teste de nivelamento é um elemento importante na maioria dos programas, devido à necessidade de alocar os alunos em grupos de capacidade linguística relativamente homogênea, às vezes dentro de áreas de habilidades específicas e diversas.

\section{Referências}

ALMEIDA FILHO, J. C. P. Dimensões comunicativas no ensino de línguas. Campinas: Pontes, 1993. 
BRASIL. Decreto $n^{0}$ 7.642, de 13 de dezembro de 2011. Institui o Programa Ciência sem Fronteiras. Diário Oficial [da República Federativa do Brasil], Brasília, DF, 13 dez. 2011. Disponível em: $<$ <ttp://www.planalto.gov.br/ccivil_03/_Ato2011-2014/2011/Decreto/D7642.htm>. Acesso em: 27 mar. 2020.

DA SILVA, Adriana Silva et al. Guia do Formador. Coleção e-Tec Idiomas sem Fronteiras. Instituto Federal de Educação, Ciência e Tecnologia Sul-Rio Grandense - IFSUL, Pelotas, RS, 2015. Disponível em:

<http://idiomas.ifsul.edu.br/conteudo/portugues/modulo_02/pdf/guias_estudante_e_formador/POR_guia _formador.pdf>. Acesso em: 20 fev. 2020.

CRISTÓVÃO, V. L. L. Reflexão sobre a prática social da fala: repensando o ensino do oral em LE. In: LEFFA, V. J. (org.). O professor de línguas estrangeiras: construindo a profissão. Pelotas: Educat, 2001, p. 307-316.

RICHARDS, J.C.; RODGERS, T. Approaches and Methods in Language Teaching. Cambridge: Cambridge University Press, 1986.

Data de submissão: 29/08/2020. Data de aprovação: 22/10/2020. 